\title{
UNA MIRADA AL RÉGIMEN ALTERNATIVO Y ACUMULATIVO DEL SISTema de acciones de LA Ley de Competencia DesLeal en la JUDICATURA NACIONAL*
}

\section{A look at the alternative AND CUMUlative REgIMe of the SYSTEM OF aCtIONS OF UNFAIR COMPETITION LAW IN THE NATIONAL JUDICIARY}

Felipe Ignacio Fernández Ortega

Trabajo recibido el 05 de diciembre de 2017 y aprobado el 08 de agosto de 2018

\section{Resumen}

Este trabajo tiene por objeto examinar el sistema de acciones de la Ley de Competencia Desleal chilena; y con ello, cuestionar si se trata de un régimen alternativo o acumulativo, o más bien dependiente. Para esto, se incorporará el tratamiento judicial que se ha dado a estas materias.

Palabras clave: Acciones del artículo 5 de la Ley de Competencia Desleal; régimen alternativo o acumulativo; régimen dependiente.

\section{Abstract}

The purpose of this paper is to examine the system of actions of the Chilean Unfair Competition Law, in order to determine whether it is either alternative or cumulative regime, or rather a dependent regime. For this task, the usual judicial treatment given to these matters will be incorporated.

Keywords: Actions of article 5 of the Law on Unfair Competition; alternative or cumulative regime; dependent regime.

\section{INTRODUCCIÓN}

La Ley No 20.169, que regula la Competencia Desleal de 2007', tiene por objeto proteger a los competidores, consumidores y, en general, a cualquier persona afectada en sus intereses legítimos por un acto de competencia desleal (artículo 1 LCD). Es una tutela amplia, no circunscrita a competidores, que

En adelante, indistintamente LCD o Ley.

* Felipe Ignacio Fernández Ortega. Profesor de Derecho del Consumo, Universidad Diego Portales, Santiago, Chile. Correo de contacto, felipe.fernandezo@mail.udp.cl.

Este trabajo fue presentado en el II Congreso Internacional de Regulación y Consumo, organizado por la Universidad Autónoma y el Centro de Regulación y Consumo de la misma casa de estudios, el 12 de julio de 2017. 
se extiende a otros agentes del mercado².

Esta protección se cristaliza en el artículo 5 LCD a través de un régimen de cuatro acciones: 1) la acción de cesación o de prohibición; 2) la acción declarativa; 3) la acción de remoción de efectos; y 4) la acción de indemnización de perjuicios. Y, según la misma norma, éstas se pueden ejercer conjunta o separadamente ${ }^{3}$.

No obstante lo anterior, la praxis judicial demuestra que en realidad, el régimen de acciones depende de la acción declarativa. Así, el sistema más allá de ser alternativo o acumulativo, es más bien dependiente; y luego recién acumulativo o alternativo. El problema de esto, es que los jueces han desestimado acciones por no interponer la acción declarativa ${ }^{4}$.

En las líneas que siguen se intentará explicar cómo opera el régimen de acciones del que disponen las víctimas de un acto de competencia desleal, incorporando para ello su tratamiento judicial, con los problemas que se han suscitado. Y luego, a raíz de ese estudio, se examinará la idea que se trataría de un régimen alternativo y acumulativo, para proponer que, en realidad se trata, al menos en parte, sólo de un régimen dependiente, en atención a la acción declaratoria.

\section{LAS ACCIONES DE LA LEY DE COMPETENCIA DESLEAL}

\section{A continuación, se revisarán cada una de las acciones del artículo 5 LCD.}

Así, en primer lugar, corresponde examinar el artículo 5 letra a), que consagra la "acción de cesación del acto o de prohibición del mismo si aún no se ha puesto en práctica".

\footnotetext{
2 Como lo reconocen Contreras (2012), 97; y Bernet (2014), 401, la LCD adoptó el denominado "modelo social de competencia desleal". Este modelo se caracteriza por proteger el orden económico del mercado en función de distintos intereses, de los competidores, de los consumidores y el interés público del Estado. MenénDEZ (1988) 96. Su adopción implica que desaparezca como requisito de aplicación de la ley la relación de competencia, pues como con este modelo se protege a otros sujetos, no competidores, no puede sino eliminarse dicha exigencia. Menéndez (1988), 118-119.

3 En concreto, la norma lo establece en los siguientes términos:

"Artículo 5.- Contra los actos de competencia desleal pueden ejercerse, conjunta o separadamente, las siguientes acciones:

a) Acción de cesación del acto o de prohibición del mismo si aún no se ha puesto en práctica.

b) Acción declarativa de acto de competencia desleal, si la perturbación creada por el mismo subsiste.

c) Acción de remoción de los efectos producidos por el acto, mediante la publicación de la sentencia condenatoria o de una rectificación a costa del autor del ilícito u otro medio idóneo.

d) Acción de indemnización de los perjuicios ocasionados por el acto, sujeta a las disposiciones del Título XXXV del Libro IV del Código Civil".

4 En general, las demandas incluyen la acción declarativa y alguna otra, como la de cesación o la indemnizatoria, toda vez que estas últimas requieren, que se haya acreditado en forma previa que se cometió un acto de competencia desleal. Por ejemplo, en Conveyor Belt Technology Ltda con Veyande Technologies Chile Limitada (2014) se demandó la acción declarativa y la de remoción de efectos; en Preuniversitario Pedro de Valdivia Limitada con Establecimientos educacionaleslaej limitada (2013) se demandó la acción de cesación, declarativa y de remoción de efectos; en L'Oreal con Laboratorios Prater S.A. (2014) se demandó la acción declarativa, de cesación e indemnización de perjuicios. Así también se conocen sentencias en las que se demandó se demandó solicitando la condena por las cuatro acciones que consagra el artículo 50: Gutiirrez con D.A Sociedad Fomento Agrícola Asociación (2013); Columbia Sportswear Company con Comercial Windsor Ltda. (2012); Philip Morris produ con Comercial (2012). Asimismo, entre otras, en las siguientes sentencias se demandó solicitando la condena del demandado por las acciones a), b) y c) del artículo 5. Es decir, se excluyó la indemnización de perjuicios: Fundación cultural con Embotellad (2009); Prolam con Sánchez (2012).
}

FERNÁNDEZ ORTEGA, Felipe Ignacio. Una mirada al régimen alternativo y acumulativo del sistema de acciones de la Ley de Competencia Desleal en la judicatura nacional. Revista Justicia y Derecho, Santiago, v. 1, n 1, 2018 


\subsection{Acción de cesación o prohibición}

Según el tenor de la norma la condena a cesar podrá comprender una orden de cesación en sentido estricto que implica la paralización del acto; o bien una prohibición de poner en práctica un determinado acto de competencia desleal ${ }^{5}$.

Se trata de acciones inhibitorias, que tienen por objeto paralizar el ilícito, de manera tal que su naturaleza es preventiva y provisional. Buscan inhibir el acto desleal desplegado ${ }^{6}$, para evitar la producción del daño ${ }^{7}$. Lo que se pretende es que un acto deje de realizarse o que no se produzca.

Como se puede advertir, se trata en realidad de dos acciones. Por eso, para continuar es preciso diferenciarlas. Y el criterio para ello es si el acto de competencia desleal, en palabras de la ley, se ha puesto o no en práctica. Con la primera, se busca la cesación del acto que ya produjo efectos, y con la segunda el objetivo será la prohibición que se ejecute un acto futuro. Si bien con ambas se apunta a inhibir conductas desleales, la diferencia radicará en que en la cesación la actuación está ocurriendo y produciendo sus efectos, mientras que en la prohibición es una actuación futura que se busca evitar que aparezca en el mercado ${ }^{8}$.

Explicado esto, corresponde precisar los requisitos de procedencia de cada una de ellas.

Por una parte, la acción de cesación, siguiendo a MASSAGUER, se compone de dos presupuestos, a saber: "[1] la realización efectiva o inminente del acto de competencia desleal y [2], en caso de efectiva realización, un riesgo objetivo de repetición o continuación"9. Así, se deberá acreditar que se incurrió en un ilícito ex artículo 3 o 4 LCD. Y, además, que existe un riesgo objetivo de repetición. Si se satisfacen ambos presupuestos el juez podría ordenar la cesación de la conducta.

Sin embargo, en la práctica judicial estos requisitos son más bien difusos, pues en general los tribunales que acogen estas acciones lo hacen sólo acreditando que se incurrió en un acto de competencia desleal ${ }^{10}$. Con ello, se ordena el cese de la conducta, e incluso en algunos casos el cese y la prohibición de incurrir en ellos en el futuro.

Un típico ejemplo en que se ejerce la acción de cesación es en los casos de publicidad que se regulan en la ley de competencia desleal, ya sea a través de publicidad comparativa, o publicidad engañosa. En estos casos, si se acreditan los requisitos del acto de competencia desleal en particular, procede el cese de la conducta, que se traduce en ordenar que se abstenga de emitir, en diversos medios, la cuestionada publicidad o el producto conforme al cual se produce el engaño ${ }^{11}$. Esto es lo mismo que pasa en sede de

5 Massaguer (1997), 105-106.

6 Poblete (2007), 167. En el mismo sentido, Contreras (2012), 167.

7 Poblete (2007), 100.

8 BARONA (1999), 136

9 Massaguer (1997), 105.

10 En este sentido, en Acepta.com S.A. con South Consulti (2012) el tribunal acogió la acción de cesación y las demás invocadas por el actor al verificar la realización del ilícito desleal. En resumen, los hechos que dieron origen al caso son que la demandante, dueña de ciertas marcas, se percató que la demandada había promocionado sus servicios a través de la página web de Google utilizando estas marcas provocando la desviación de su clientela. Se alegó el acto de competencia desleal general ex artículo $3^{\circ}$ y el ilícito especial del artículo $4^{\circ}$ letra a). El tribunal se centró en analizar si la conducta alega era calificable de desleal conforme a la LCD. Luego, una vez que acreditó dicha circunstancia sólo señaló que: "... se procederá a acoger la demanda, en cuanto la demandada SouthConsulting debe cesar dichos actos de competencia desleal y de violación de los derechos de propiedad industrial de las demandantes, quedándole expresamente prohibido a ésta cualquier utilización económica de las marcas o denominaciones 'Acepta,' 'Azurian', 'Dbnet' o 'Paperless'”' (considerando sexagésimo cuarto). En este caso, se decretó tanto la cesación del acto como la prohibición del mismo.

11 En efecto, en L'Oreal con Laboratorios Prater S.A. (2016) el actor alegó que el demandado incurrió en dos actos de competencia desleal. El primero conforme al artículo 4 letra a) pues comercializó un perfume en un envase similar al de su producto

FERNÁNDEZ ORTEGA, Felipe Ignacio. Una mirada al régimen alternativo y acumulativo del sistema de acciones de la Ley de Competencia Desleal en la judicatura nacional. Revista Justicia y Derecho, Santiago, v. 1, n 1, 2018 
consumo con la publicidad engañosa.

Y, por otra parte, la acción de prohibición se configura por tres elementos: 1) la concurrencia previsible de una actuación desleal; 2) un perjuicio futuro; y 3) el peligro de iniciación ${ }^{12}$. En este caso se atiende a criterios futuros, y lo que interesa es que la actuación ocurrirá o podría ocurrir.

Aquí sólo será necesario acreditar la potencialidad o idoneidad de la conducta desleal en miras a que pueda causar un perjuicio. Con ello, la acción de prohibición será justificada y por tanto procederá contra el acto. El objetivo es evitar daños futuros, por lo que bastaría la mera probabilidad que la conducta pueda producir daños para que proceda la tutela jurisdiccional ${ }^{13}$. En definitiva, ante riesgos o perjuicios inminentes se debería decretar la prohibición de la realización del acto.

No se conocen sentencias en que se haya solicitado sólo la acción de prohibición, sólo algunos casos en que se ha pedido el cese y la prohibición en conjunto, pero ello apunta a la prohibición de repetición, no de incurrir en el acto.

Dicho esto, a continuación me corresponde examinar el artículo 50 letra b) que consagra la "acción declarativa de acto de competencia desleal, si la perturbación creada por el mismo subsiste".

\subsection{Acción declarativa}

Se trata de una acción a través de la cual el actor busca la constatación judicial y la respectiva declaración que el agente acusado ha cometido un acto de competencia desleal14.

Para conseguir la tutela declarativa se deberá demostrar la concurrencia de dos presupuestos: 1) que en efecto exista un acto de competencia desleal; y 2) que el actor tenga un interés legítimo tutelable ${ }^{15}$.

Respecto del acto de competencia desleal se podrá acreditar la conducta conforme al artículo 3, que contempla una especie de cláusula general, o al artículo 4, con los ilícitos especiales: publicidad engañosa o comparativa, incumplimiento sistemático de deberes contractuales, abuso de acciones judiciales, cláusulas abusivas, entre otros. Esta es la acción más aplicada porque sirve de base al sistema.

Con todo, es preciso señalar que de la revisión de sentencias y del análisis que realizan los tribunales al conocer de esta acción, es posible apreciar que, en algunos casos, aislados, se ha exigido un tercer requisito: que el actor y el demandado sean competidores ${ }^{16}$. Así, se ha declarado improcedente la acción

y se usaron nombres similares a otros productos del actor. Y el segundo, el ilícito del artículo 4 letra b), fundado en los mismos motivos. El tribunal de primera instancia acogió la demanda y declaró que el demandado incurrió en actos de competencia desleal; se condenó al cese de dichos actos, a la abstención de comercializar los productos; a retirarlos del mercado; y a indemnizar perjuicios. Contra esta sentencia la parte demandada interpuso recurso de casación en la forma y apelación. La Corte de Apelaciones de Santiago rechazó ambos. El demandado interpuso recurso de casación en el fondo, el que fue rechazado por la Corte Suprema. Así las cosas, en este caso al demandado se le ordenó la abstención de continuar comercializando el producto en cuestión y a retirarlo del mercado. Esa fue, precisamente, la condena conforme a la acción de cesación.

12 Barona (1999), 134-137.

13 Contreras (2012), 168.

14 Como señaló LaTHROP a propósito del dominio, con las acciones declarativas se "persigue no una condena del demandado ni la constitución de nuevas relaciones jurídicas o la alteración de un estado de hecho preexistente, sino la declaración de una determinada relación de derecho puesta en duda o discutida", en LATHROP (2011), p. 10.

15 Tato, Fernández y HerRera (2010), 352.

16 Si bien no se trata de una tendencia consolidada, hay algunos fallos aislados que erróneamente exigen este requisito. Así, en Rial Automóbil Club de Catalunya RACC (España) y otro con RAC asistencia S.A. (Chile) y otro (2015) se expresó que: "ambas actoras olvidan un presupuesto basal en este tipo de controversias: para que pueda existir un acto de competencia desleal es necesario que ambos agentes compitan en el mismo mercado. [...] sin este requisito es improcedente una declaración de acto de competencia desleal". Por ello se desechó la demanda.

FERNÁNDEZ ORTEGA, Felipe Ignacio. Una mirada al régimen alternativo y acumulativo del sistema de acciones de la Ley de Competencia Desleal en la judicatura nacional. Revista Justicia y Derecho, Santiago, v. 1, no 1, 2018 
declarativa porque el demandante y demandado no eran competencia uno del otro.

Sin embargo, esta exigencia es criticable ${ }^{17}$. Si la ley protege a consumidores y en general a cualquier afectado en sus intereses legítimos, parece ser más bien que el factor determinante estará en el interés legítimo, no en si son competidores. En caso contrario, la protección de la competencia leal se vería mermada incluso entre empresarios pues si no compiten por la misma clientela no podrían ejercer esta acción. Peor aún es el caso de los consumidores y los afectados en sus intereses legítimos, pues siguiendo la postura planteada, en ningún caso podrían obtener tutela judicial.

Las sentencias que adoptan esta postura reflejan uno de los principales problemas de la LCD chilena, que se relaciona con la adopción del modelo social de competencia desleal del artículo 1 y su relación con los demás artículos de la ley, en particular con el artículo 3 que daría a entender, por la exigencia de la desviación de clientela, que debe existir una relación de competencia. Sin embargo, el análisis de esta cuestión se escapa de lo que se pretende examinar en este trabajo. Con todo, en líneas generales, lo que importa entender sobre este punto, es que la relación de competencia en leyes que adoptan el modelo social, como la chilena, no puede ser un requisito de aplicación de la ley, porque dicha exigencia se relaciona con otros modelos, como el profesional. Entenderlo de una manera diversa, provoca una distorsión en el régimen legal.

Ahora, para avanzar, corresponde referirse al artículo 5 letra c) que consagra la "acción de remoción de los efectos producidos por el acto, mediante la publicación de la sentencia condenatoria o de una rectificación a costa del autor del ilícito u otro medio idóneo".

\subsection{Acción de remoción de efectos producidos por el acto}

Se trata de una acción de condena. Se busca que el Juez obligue a quien realizó el acto de competencia desleal a ejecutar determinados actos que tengan por finalidad eliminar los efectos subsistentes y dañinos del ilícito ${ }^{18-19}$.

Respecto de sus requisitos de procedencia, el actor debe probar la existencia de los efectos ocasionados por un acto desleal y su vigencia en el momento de presentarse la demanda ${ }^{20}$. Además, se requiere que los efectos distorsionen la competencia ${ }^{21}$, y que los efectos continúen en el tiempo, pues en caso contrario desaparecería la causa de la acción, ya que no habría nada que eliminar²2.

Así las cosas, en este caso será necesario, en primer lugar, que el acto se haya materializado²3. Sólo así se podrán remover los efectos que produjo el ilícito. En caso contrario, no habría nada que remover y

Véase también, por ejemplo, Fundación Cultural con Embotellad (2009), considerandos décimo y undécimo.

17 En nuestro medio, BERNET, a propósito del análisis del ámbito de aplicación de la LCD, señaló que la relación de competencia (es decir, los actos que afectan a los intereses de los competidores) no se debe considerar como una condición necesaria para acceder a la tutela de la Ley. Bernet (2014), 418-424. En el mismo sentido, Contreras (2012), 88-89.

18 Poblete (2007), 105.

19 En este sentido, en Wac Research S.A. con Octogone Chile S.A y Octogone gestion S.A (2014) el Tribunal señaló en forma expresa que: "Esta acción tiene por objeto la reconstitución del status quo anterior a la realización del acto de competencia desleal, esto es, la necesidad de la eliminación de los efectos subsistentes y dañinos de la deslealtad. [...] Al efecto, la hipótesis descrita en la ley, considera una pretensión genérica de efectos perturbadores, cuya extensión debe determinarse en cada caso, considerando la especie de efectos de la conducta desleal de que se trate, además de otras pretensiones específicas de remoción vinculadas con la comunicación e información" (considerando septuagésimo primero).

20 Tato, Fernández y Herrera (2010), 367.

21 Massaguer (1997), 106.

22 ZURILLA (2009), 10.

23 En el mismo sentido, Tato, Fernández y Herrera (2010), 368.

FERNÁNDEZ ORTEGA, Felipe Ignacio. Una mirada al régimen alternativo y acumulativo del sistema de acciones de la Ley de Competencia Desleal en la judicatura nacional. Revista Justicia y Derecho, Santiago, v. 1, no 1, 2018 
la pretensión del actor se debiera ver satisfecha sólo con la prohibición del acto, que atiende a criterios futuros, es decir, a actos que no se han puesto en práctica.

En segundo lugar, se requerirá que en forma previa se haya determinado la ilicitud del acto, es decir que se haya declarado que el acto es desleal ${ }^{24}$, en un juicio anterior o en el mismo. En este sentido, se ha sentenciado que la adopción de medidas de remoción de los efectos de un acto de competencia desleal, requiere que el acto mismo se haya declarado como desleal, pues en caso contrario, resulta inútil referirse a la acción de remoción si no hay ilícito que haya producido efectos perversos en el mercado 25 .

Sobre la forma en que se materializa esta acción, el artículo en estudio se refiere a la publicación de la sentencia condenatoria o la rectificación a costa del deudor del ilícito u otros medios. En general, de las sentencias en las que se acoge esta acción se puede ver que la tendencia es que se condena a la publicación de la sentencia o de un extracto de la misma en uno o más medios de comunicación escritos de circulación nacional, e incluso, en medios internacionales ${ }^{26}$. Con todo, la norma posibilita al actor a solicitar la remoción de efectos de una manera distinta. Sin embargo, no se conocen sentencias en que esto haya sido así. En estos casos, el contenido de la remoción, es decir, qué efectos se eliminarán, sólo se podrán determinar caso a caso, pues se debe atender a qué efectos concretos produjo el acto desleal. Sólo así se podrá lograr reconstituir el statu quo anterior a su realización²7.

Así las cosas, para finalizar esta parte, corresponde que referirse al artículo 5 letra d), que consagra la "acción de indemnización de los perjuicios ocasionados por el acto, sujeta a las disposiciones del Título XXXV del Libro IV del Código Civil".

\subsection{Acción indemnizatoria}

Se trata también de una acción de condena, pues el agente que provocó el acto de competencia desleal estará obligado a conceder una prestación dineraria al agente afectado si se acredita que se ha incurrido en el ilícito ${ }^{28}$.

La ley señala que esta acción se sujetará a las disposiciones de la responsabilidad extracontractual del Código Civil. Por tanto, los requisitos para que proceda la acción son: 1) acreditar la existencia de un hecho o acto; 2) analizar la imputación subjetiva correspondiente; 3) acreditar la producción del daño; y

\footnotetext{
24 Poblete (2007), 105. En el mismo sentido, véase Tato, Fernández y Herrera (2010), 365.

25 Así, en Laboratorios Andrómaco S.A. con Danone de Chile S.A. (2016) se interpuso un recurso de casación en la forma contra la sentencia de primera instancia, fundado, en lo que interesa, en que se dedujeron tres acciones y que el fallo sólo hacía referencia a una única pretensión sin decidir sobre cada una de las acciones que se habían ejercido. Sobre este punto la C.A de Santiago señaló:"... habiéndose denegado la declaración de actos de competencia desleal, de los que necesariamente derivaría la adopción de medidas de remoción de los efectos de esos actos - por ello inútil se hace una alusión específica a esa parte de la petición- más improcedente aun resulta un pronunciamiento sobre los supuestos daños que habrían causado actos que se tuvieron por no cometidos" (considerando tercero) (énfasis añadido). De esta manera, la Corte en forma expresa señala que la acción de remoción de los efectos deriva de la previa declaración del acto de competencia desleal.

26 Por todas, Columbia Sportswear Company con Comercial Windors Ltda. (2012). En este caso el Tribunal señaló: "Que se ha solicitado, además por el actor, la remoción de los efectos producidos con los actos de competencia desleal que dieron origen a este juicio, y para ello solicita que se publique un extracto de la presente sentencia en los diarios 'El Mercurio'y 'La Tercera', por al menos tres veces, durante días domingos y festivos, a costas del demandado, y que se de cumplimiento, a la letra C) del artículo $5^{\circ}$ de la ley 20.169 publicándose dicho extracto, además, en un lugar visible y destacado de cada uno de los locales donde se comercializan los productos que contienen etiquetas similares a la de su representada.

Que habiéndose establecido por esta sentencia la existencia de actos de competencia desleal denunciados, se deberá acceder también a la pretensión de la demandante en el sentido que las demandadas deberán efectuar las publicaciones referidas en el motivo precedente" (considerando vigésimo quinto y sexto).

27 Darnaculleta I Gardella (2007), 75.

28 Poblete (2007), 106.
}

FERNÁNDEZ ORTEGA, Felipe Ignacio. Una mirada al régimen alternativo y acumulativo del sistema de acciones de la Ley de Competencia Desleal en la judicatura nacional. Revista Justicia y Derecho, Santiago, v. 1, n 1, 2018 
4), demostrar la relación de causalidad entre la conducta y el daño ${ }^{29}$. Por razones de tiempo, a continuación, se examinará sólo uno de los requisitos de este estatuto de responsabilidad, esto es, la imputación subjetiva pues es el único que presenta ciertas dificultades, en la doctrina y en la judicatura.

Al respecto, en Chile se ha discutido ${ }^{30}$ si la tutela indemnizatoria en esta sede se rige por las reglas generales, es decir, se exige culpa o dolo ${ }^{31}$, o bien si se requiere que el ilícito se haya cometido con dolo o culpa grave ${ }^{32}$. Se coincide con esta última postura, pues no cualquier infracción al deber de cuidado debe establecer el régimen de culpa en esta sede, pues se debe mantener un equilibrio entre la libertad de competencia y la responsabilidad civil. Esto significa que, para acceder a la tutela indemnizatoria se deberá demostrar la intención de causar daño, o al menos, la grave desconsideración del demandado.

Respecto de este punto, en la revisión de sentencias también es posible encontrar opiniones dispares respecto a qué elementos configuran la imputación subjetiva. Con todo, es necesario reconocer que de dicho análisis es posible concluir que la tendencia jurisprudencial tiende más bien a reconocer que se requiere culpa o dolo ${ }^{33-34}$.

Con estas palabras finaliza el examen al régimen de acciones de la LCD. De esta manera, para terminar, sólo resta referirse a un último aspecto, esto es, a la idea que el régimen de acciones consagrado en la ley es alternativo y acumulativo a la vez.

\section{El RÉGIMEN ALTERNATIVO Y ACUMULATIVO dE ACCIONES EN LA LCD}

El artículo 5 señala que el afectado por un ilícito desleal podrá impetrar estas acciones conjunta o separadamente. Esto significa que se puede ejercer sólo una de ellas, algunas o todas en la misma demanda. Se trataría, entonces, de un régimen alternativo y acumulativo a la vez, toda vez que el afectado podría optar por incoar sólo una acción, o bien acumular algunas o todas ellas; tal como ocurre, por ejemplo, en el sistema de remedios del régimen contractual del artículo 1489 del Código Civil, o en los artículos 19 y 20 de la Ley No 19.496 sobre protección de los derechos de los consumidores, de 1997. De esta manera la lógica de las acciones siempre piensa en la acumulación de las mismas, pero sin atender a la dependencia de una a otra.

\footnotetext{
29 Por todos, BarRos (2009), 61-62. El desarrollo pormenorizado de cada requisito, en la misma obra citada, BARROs (2009), 63444.

30 Dicha discusión se da porque en esta parte la normativa chilena se apartó de la LCD española que sirvió de fundamento para la LCD. La diferencia radica en que la norma española se consagra en los siguientes términos: “5. a Acción de resarcimiento de los daños y perjuicios ocasionados por el acto, si ha intervenido dolo o culpa del agente" (esta parte de la disposición no ha sido modificada desde 1991. Ley disponible en www.boe.es). Como se puede apreciar, el legislador nacional no optó por mantener esa fórmula.

31 En este sentido Bernet (2014), 435.

32 BANFI (2014) 40-41.

33 En este sentido, entre otras, véase: Desarrollo de tecnologías y sistemas limitada con sociedad Holdtech S.A. (2015), considerando trigésimo primero; Acepta.com S.A. con South consulti (2012), considerando sexagésimo segundo; Car Freshner corporation con laboratorio Barik y Cía. Ltda. (2013), considerando vigésimo primero; Sociedad metalúrgica Quiqonesfarfan Ltda. con Tresmontes Lucchetti S.A. (2012), considerando octavo.

34 En contra, por ejemplo, está el caso Importadora y distribuidora Santiago S.A. con Contreras (2012), confirmada por la Tercera Sala de la Corte de Apelaciones de Santiago, Rol 2097-2012, 26 de septiembre de 2013). Aquí se deniega la indemnización de perjuicios: "por cuanto para determinar si existe derecho a indemnización de perjuicios [...] debe primeramente establecerse la concurrencia de una conducta dolosa de parte del demandado, el daño sufrido por la actora y el vínculo causal entre ambas circunstancias, y en el presente caso los dos últimos elementos no han sido acreditados por la demandante" (énfasis añadido). Así, el tribunal reconoce que para configurar la imputación subjetiva de la indemnización de perjuicios en sede de competencia desleal se requiere una actuación dolosa por parte del agente.
}

FERNÁNDEZ ORTEGA, Felipe Ignacio. Una mirada al régimen alternativo y acumulativo del sistema de acciones de la Ley de Competencia Desleal en la judicatura nacional. Revista Justicia y Derecho, Santiago, v. 1, n 1, 2018 
Sin embargo, tomando en consideración lo que se ha señalado en la revisión de las acciones, por la fisonomía de éstas, tienen como presupuesto el ejercicio previo de la acción declarativa. Esto significa que, en realidad, puede cuestionarse si es necesaria o no la dependencia a esta acción para que el régimen opere alternativamente.

En este sentido, en forma acertada se ha fallado por nuestros tribunales en diversos casos. Así, se ha sentenciado que, si no se ha acredita que el acto alegado califica como desleal, es inocuo referirse a la acción de remoción de efectos.

La lógica que existe detrás del razonamiento judicial, es que para que exista una conducta a cesar, efectos que remover o perjuicios que indemnizar, es preciso que exista un acto de competencia desleal, determinado a través de la acción declarativa.

De esta manera, estas acciones deben ejercerse en conjunto con la acción declarativa, pues, en caso contrario, se declararán improcedentes.

Así las cosas, a pesar que el legislador consagró el régimen de acciones de manera tal que se pueden ejercer en forma conjunta o separada, por los requisitos propios de la acción de cesación, remoción e indemnizatoria, se trata de un régimen dependiente a la acción declaratoria.

En otras palabras, la idea de un régimen alternativo y acumulativo en realidad es parcial.

Lo expuesto significa que, en realidad, las acciones son alternativas entre la acción declarativa y de prohibición, pues ellas se pueden ejercer de forma independiente de las demás. Y luego, que se pueden acumular, o en palabras de la ley, ejercer en forma conjunta, con las acciones de cesación, remoción e indemnizatoria, según corresponda, y de conformidad a los intereses del afectado.

Así expuestas las cosas, esta cuestión lleva a preguntarse si es que en realidad es necesaria esta acción en el régimen del artículo 5 o bien, más que una acción propiamente tal, es un presupuesto de las demás acciones del sistema.

\section{Conclusiones}

El régimen de acciones estudiado es adecuado para la protección de la competencia leal entre los agentes del mercado. Como se ha intentado mostrar, en la judicatura se presentan problemas menores.

En resumen, en la acción de cesación o prohibición del acto, la interpretación que han dado los tribunales simplifica los requisitos de dichas acciones a favor del afectado, limitándolo sólo a que se haya incurrido en un acto de competencia desleal.

Por su parte, respecto de la acción declarativa se ha criticado la exigencia, aislada en algunos fallos, de condicionar la acción a que demandante y demandando sean competidores. El problema conforme al modelo social de competencia desleal adoptado en la ley la relación de competencia no es, ni puede ser, un requisito de aplicación de LCD; por ello, los jueces, en estos fallos, yerran al exigir que ambas partes sean competidores.

En la acción de remoción de efectos, la revisión de sentencias también muestra que se exige sólo que se haya declarado que se cometió un acto de competencia desleal, y que es necesario que el acto se haya materializado. Asimismo, se ha mostrado que la tendencia es que se condena a la publicación de la sentencia o de un extracto de ella en uno o más medios de comunicación escrito, a pesar que, según la

FERNÁNDEZ ORTEGA, Felipe Ignacio. Una mirada al régimen alternativo y acumulativo del sistema de acciones de la Ley de Competencia Desleal en la judicatura nacional. Revista Justicia y Derecho, Santiago, v. 1, n 1, 2018 
norma, se podría pedir otra forma de remoción de efectos.

Respecto de la acción indemnizatoria se ha señalado que se presenta un principal problema, relativo a la imputación subjetiva, pues es preciso determinar si se exige culpa o dolo, o bien dolo o al menos culpa grave para que proceda la tutela indemnizatoria. Así, si bien se abogó por esta última postura, la tendencia jurisprudencial mayoritaria exige culpa o dolo.

Y, por último, tras el examen de las cuatro acciones se ha intentado mostrar que el régimen alternativo y acumulativo que se expresa en el artículo 5 es sólo parcial. Esto, pues la acción declarativa sería en realidad un presupuesto de la acción de cesación, de remoción e indemnizatoria, toda vez que para que éstas sean procedentes se requiere que se haya acreditado que el acto alegado califica como de competencia desleal. De esta manera, la idea de un régimen alternativo y acumulativo en realidad es parcial pues en el régimen de acciones existe una dependencia de la acción declarativa.

\section{Bibliografía Citada}

BANFI, Cristian (2014): "Acerca de la imputación de responsabilidad civil por ilícitos anticompetitivos entre rivales en Chile", Revista Chilena de Derecho, vol. 41, № 1: pp. 37-58.

Barona, Silvia (1999): Competencia desleal (Valencia, Tirant lo Blanch, segunda edición).

BARRos, Enrique (2009): Tratado de responsabilidad extracontractual (Santiago, Jurídica).

Bernet, Manuel (2014): La presentación comercial en el derecho de la competencia desleal (Santiago, LegalPublishing).

CONTRERAS, Óscar (2012): La competencia desleal y el deber de corrección en la ley chilena (Santiago, Ediciones Universidad Católica de Chile).

Darnaculleta I Gardella, M. Mercè (2007): La competencia desleal (Madrid, lustel).

LATHROP, Fabiola (2011): "Procedencia de la acción meramente declarativa del dominio en el Derecho chileno", lus et Praxis, año 17, № 2: pp. 3-24.

MASSAGUer, José (1997): "La acción de competencia desleal en el derecho español", THEMIS-Revista de Derecho, № 36: pp. 103-118.

MenÉndez, Aurelio (1988): La competencia desleal (Madrid, Civitas).

Poblete, Orlando (2007): "El proceso civil de competencia desleal" en GonzÁlez, Marco Antonio (editor), Competencia Desleal, Cuadernos de Extensión Jurídica 14 (Santiago, Universidad de los Andes).

Tato, Anxo; Fernández, Pablo; y Herrera, Christian (2010): La reforma a la ley de competencia desleal (Madrid, La Ley).

ZURILLA, María Ángeles (2009): "Acciones civiles en materia de competencia desleal”, Documento de trabajo. Seminario permanente de ciencias sociales, Cuenca: Facultad de Ciencias Sociales de Cuenca, Universidad de Castilla - La Mancha: pp. 1-23.

FERNÁNDEZ ORTEGA, Felipe Ignacio. Una mirada al régimen alternativo y acumulativo del sistema de acciones de la Ley de Competencia Desleal en la judicatura nacional. Revista Justicia y Derecho, Santiago, v. 1, nº 1, 2018 


\section{NORMAS CITADAS}

CódIGo CIVIL, vigésimo segunda edición.

LEY No 19.496 (07/03/1997) Ley que establece normas sobre protección de los derechos de los consumidores.

Ley No 20.169 (16/02/2007) Ley que regula la competencia desleal.

\section{JURISPRUDENCIA CITADA}

Acepta.com S.A. con South Consulti (2012): 30 Juzgado Civil de Santiago, 28 de noviembre de 2012, Rol № C-55530-2009, VLEX-569645130.

Car Freshner corporation con laboratorio Barik y Cía. Ltda. (2013): 10 Juzgado de Letras de San Bernardo, 23 de abril de 2013, Rol 298-2011, VLEX-565181534.

Columbia Sportswear Company con Comercial Windsor Ltda. (2012): 190 Juzgado Civil de Santiago, 26 de enero de 2012, Rol No 5640-2010, VLEX-568042150.

Conveyor Belt Technology Ltda con Veyande Technologies Chile Limitada (2014): 170 Juzgado Civil de Santiago, 31 de marzo de 2014, Rol No C-39444-2009.

Desarrollo de tecnologías y sistemas limitada con sociedad Holdtech S.A. (2015): 170 Juzgado Civil de Santiago, 31 de marzo de 2015, Rol No C-23573-2012, VLEX-578270570.

Fundación cultural con Embotellad (2009): 50 Juzgado Civil de Santiago, 17 de agosto de 2009, Rol № 22094-2007, VLEX-575438322.

Gutirrez con D.A Sociedad Fomento Agrícola Asociación (2013): 20 Juzgado Civil de Temuco, 15 de mayo de 2013. Rol No 1200-2011, VLEX-567619006.

Importadora y distribuidora Santiago S.A. con Contreras (2012): 90 Juzgado Civil de Santiago, 31 de enero de 2012, Rol No C-5856-2010, VLEX-565013406.

L'Oreal con Laboratorios Prater S.A (2014): 90 Juzgado Civil de Santiago, 30 de septiembre de 2014, Rol № C-51066-2012.

Laboratorios Andrómaco S.A. con Danone de Chile S.A (2016): Corte de Apelaciones de Santiago, 16 de junio de 2016, Rol 10572-2015.

Philip Morris produ con Comercial (2012): 230 Juzgado Civil de Santiago, 21 enero de 2012, Rol № 220122009, VLEX-573428878.

Preuniversitario Pedro de Valdivia Limitada con Establecimientos educacionaleslaej limitada (2013): $16^{\circ}$ Juzgado Civil de Santiago, 10 de enero de 2013, Rol No 5231-2012.

Prolam con Sánchez (2012): 80 Juzgado Civil de Santiago, 12 de julio 2012, Rol № 15139-2011, VLEX575709410.

Rial Automóbil Club de Catalunya RACC (España) y otro con RAC asistencia S.A. (Chile) y otro (2015): 220 Juzgado Civil de Santiago, 25 de febrero de 2015, Rol C-15271-2010, VLEX-573282218.

Sociedad metalúrgica Quiqonesfarfan Ltda. con Tresmontes Lucchetti S.A. (2012): 30॰ Juzgado Civil de San-

FERNÁNDEZ ORTEGA, Felipe Ignacio. Una mirada al régimen alternativo y acumulativo del sistema de acciones de la Ley de Competencia Desleal en la judicatura nacional. Revista Justicia y Derecho, Santiago, v. 1, n 1, 2018 
tiago, 14 de marzo de 2012, Rol No C-12225-2010, VLEX-571143390.

Wac Research S.A. con Octogone Chile S.A y Octogone gestion S.A (2014): 220 Juzgado Civil de Santiago, 9 de julio de 2014, Rol No C-21950-2012.

FERNÁNDEZ ORTEGA, Felipe Ignacio. Una mirada al régimen alternativo y acumulativo del sistema de acciones de la Ley de Competencia Desleal en la judicatura nacional. Revista Justicia y Derecho, Santiago, v. 1, no 1, 2018 